\title{
Ingenol Mebutate for Lentigo Maligna: A Case Report
}

\author{
Karolina Gadaldi Laurence Feldmeyer Nikhil Yawalkar Robert E. Hunger \\ Department of Dermatology, University Hospital Inselspital, University of Bern, Bern, Switzerland
}

\section{Key Words}

Ingenol mebutate $\cdot$ Lentigo maligna · Melanoma .

Treatment

\begin{abstract}
Background: Lentigo maligna (LM) is a melanoma in situ on sun-damaged skin, with a strong predilection to the head and neck area of the elderly. Many therapeutic modalities have been proposed in the treatment of this pathology, including surgery, cryotherapy, radiotherapy and topical imiquimod. Up to date surgical excision remains the treatment of choice with the lowest recurrence rate. Recently, a new topical treatment with ingenol mebutate has been described to be efficacious and well tolerated in the treatment of melanoma in situ. Objective: We sought to demonstrate that ingenol mebutate might be an efficacious and well-tolerated treatment in a patient suffering from LM on an aesthetically challenging location. Methods: Case report. Results: After therapeutic failure with imiquimod 5\% cream, a new topical treatment with ingenol mebutate gel $0.015 \%$ once daily on 3 consecutive days was initiated. Despite visible inflammation, no macroscopic lesion clearance was observed. While the first follow-up using reflectance confocal microscopy (RCM) performed at 6 weeks after the completion of the therapy showed no signs of LM, the second follow-up examination at 12 weeks using RCM and biopsy confirmed re-
\end{abstract}

currence of the lesion. Conclusion: Ingenol mebutate cannot be considered a standard treatment modality for all types of LM. Further studies are needed to evaluate the prerequisites that can ensure therapeutic success.

(c) 2016 S. Karger AG, Base

\section{Introduction}

Lentigo maligna (LM) is a melanoma in situ of chronically sun-exposed skin, particularly, of the head and neck area [1]. It develops mainly in elderly patients. When untreated, LM is associated with a 5-50\% risk of progressing to invasive LM melanoma, but the exact determinants for this transformation are still to be elucidated $[2,3]$. Many therapeutic modalities, including surgery, cryotherapy, radiotherapy and imiquimod cream, have demonstrated an efficacy in the treatment of LM [4]. Surgical excision employing safety margins (usually micrographically controlled) remains the first-line therapy for this pathology. Recently, a new topical treatment with ingenol mebutate $(0.015 \%$ gel $)$ has been described to be efficacious and well tolerated in the treatment of melanoma in situ [5].

We present a case of a patient with LM on the face who was treated with ingenol mebutate, but relapsed 3 months after treatment.

\section{KARGER}

E-Mail karger@karger.com

www.karger.com/drm
(C) 2016 S. Karger AG, Basel

$1018-8665 / 16 / 2327-0024 \$ 39.50 / 0$
Dr. Karolina Gadaldi

Department of Dermatology

University Hospital Inselspital, University of Berne

$\mathrm{CH}-3010$ Bern (Switzerland)

E-Mail karolina.gadaldi@insel.ch 

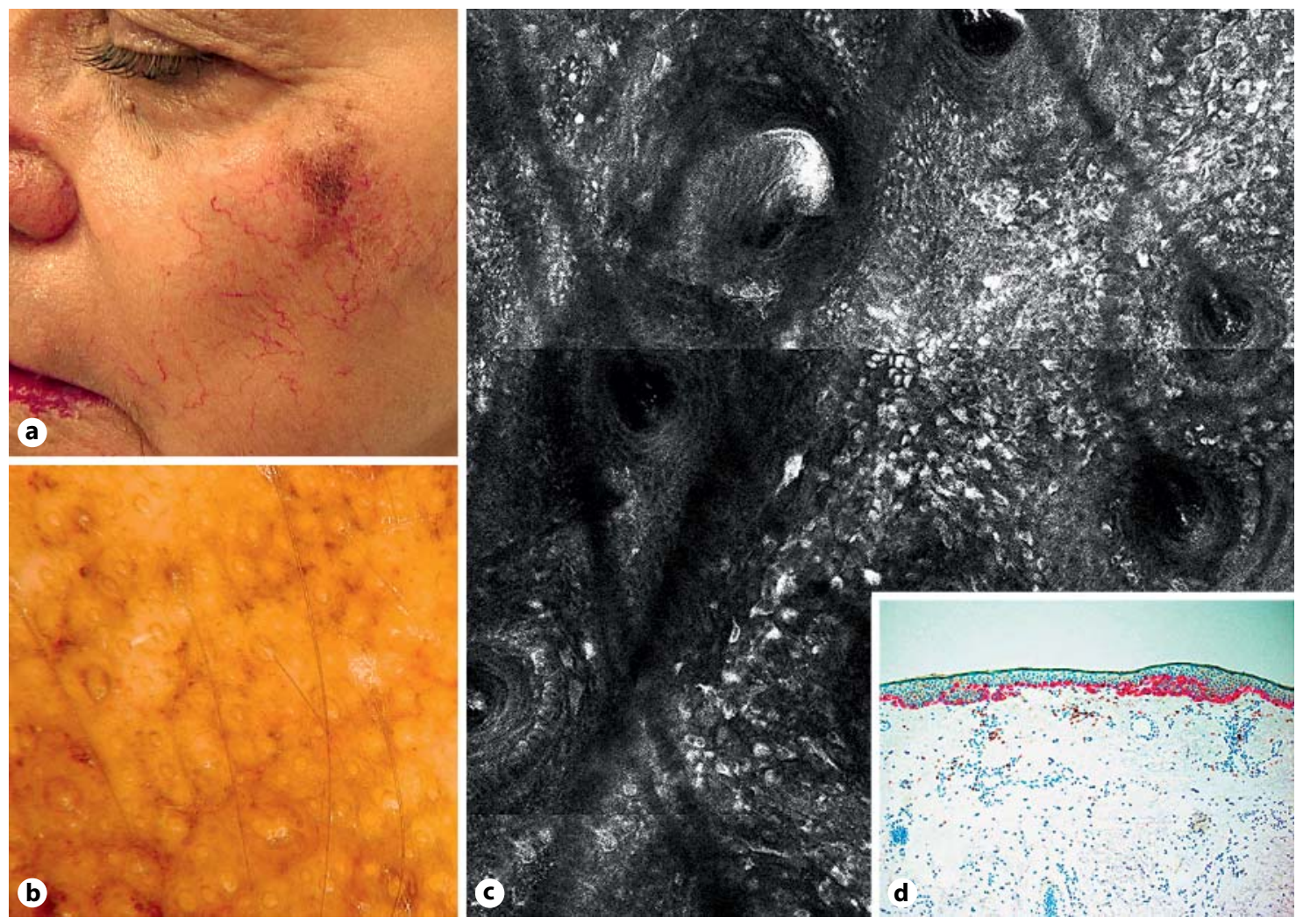

Fig. 1. Clinical (a), dermoscopic (b), confocal (c) and histological (d) picture of LM at baseline.

\section{Case Report}

A 70-year-old Caucasian woman, with a history of a multifocal hepatocellular carcinoma with pulmonary and lymph node metastases, presented to our outpatient clinic with a pigmented and slowly, but gradually enlarging macule on the face. The physical examination including dermoscopy showed a poorly demarcated light to dark brown macule measuring $2 \times 1 \mathrm{~cm}$ with black dots and asymmetric pigmented follicular openings on her left cheekbone. The lesion was further examined by reflectance confocal microscopy (RCM; Vivascope 1500, Mavig AG, Germany) revealing a disturbed architecture of the epidermis with a presence of numerous, large, round and dendritic pleomorphic cells, distributed in all epidermal layers, suggesting pagetoid spread of atypical melanocytes. An increased proliferation of atypical melanocytes was observed especially along adnexal structures. In the dermis, non-edged papillae and solar damage were the commonest findings (fig. 1). Histological examination of the 4-mm punch biopsy specimen taken in the area guided by RCM confirmed the diagnosis of LM (fig. 1).

Informed consent for image acquisition, biopsy specimen sampling and treatment (including evidence-based and off-label use) was obtained from the patient. On account of her age and comorbidities, as well as the cosmetically challenging localization and size of the lesion, the patient declined a surgery.

Therefore, an alternative treatment with imiquimod cream 5\% was initiated. The patient was instructed to apply the cream, covering the affected area and a $1-\mathrm{cm}$ margin of the surrounding skin twice daily 7 days a week. After 8 weeks of treatment, no inflammatory reaction was observed. Hence, the topical treatment was changed to ingenol mebutate gel $0.015 \%$. Three consecutive daily applications of the gel were performed on the lesion and $1 \mathrm{~cm}$ of the adjacent skin once daily for 3 days. At the end of the 3-day treatment a strong inflammatory, crusting and oozing reaction on the application site developed (fig. 2).

In the follow-up RCM examination, at 6 weeks after completion of the treatment, no criteria for LM were found. Clinically and dermoscopically, a lentiginous pigmented macule was still visible on the face (fig. 3). The follow-up examination with RCM performed after 12 weeks of treatment with ingenol mebutate showed a relapse of the LM. A 4-mm punch biopsy confirmed LM (fig. 4).

\section{Discussion}

Ingenol mebutate is a hydrophobic diterpene ester isolated from a sap of a plant Euphorbia peplus, commonly known as a 'petty spurge' in the United Kingdom or 'radium weed' in Australia, that has a long tradition of use for a variety of conditions, including skin cancer [6]. Ingenol mebutate has been registered in the USA 
Fig. 2. Strong local inflammatory response after the treatment with ingenol mebutate.
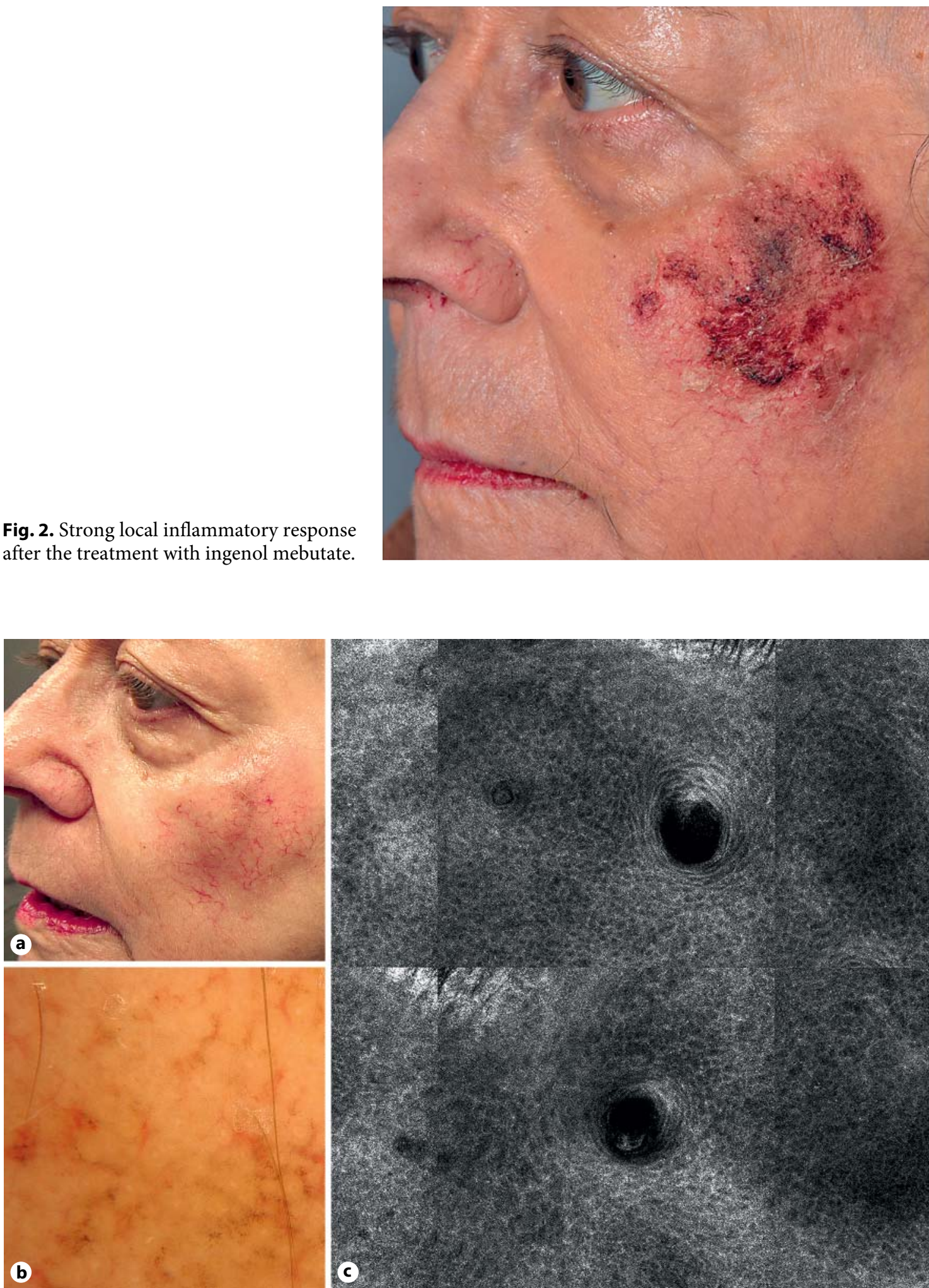

Fig. 3. Clinical (a), dermoscopic (b) and confocal picture (c) of LM at 6 weeks after the treatment with ingenol mebutate. 

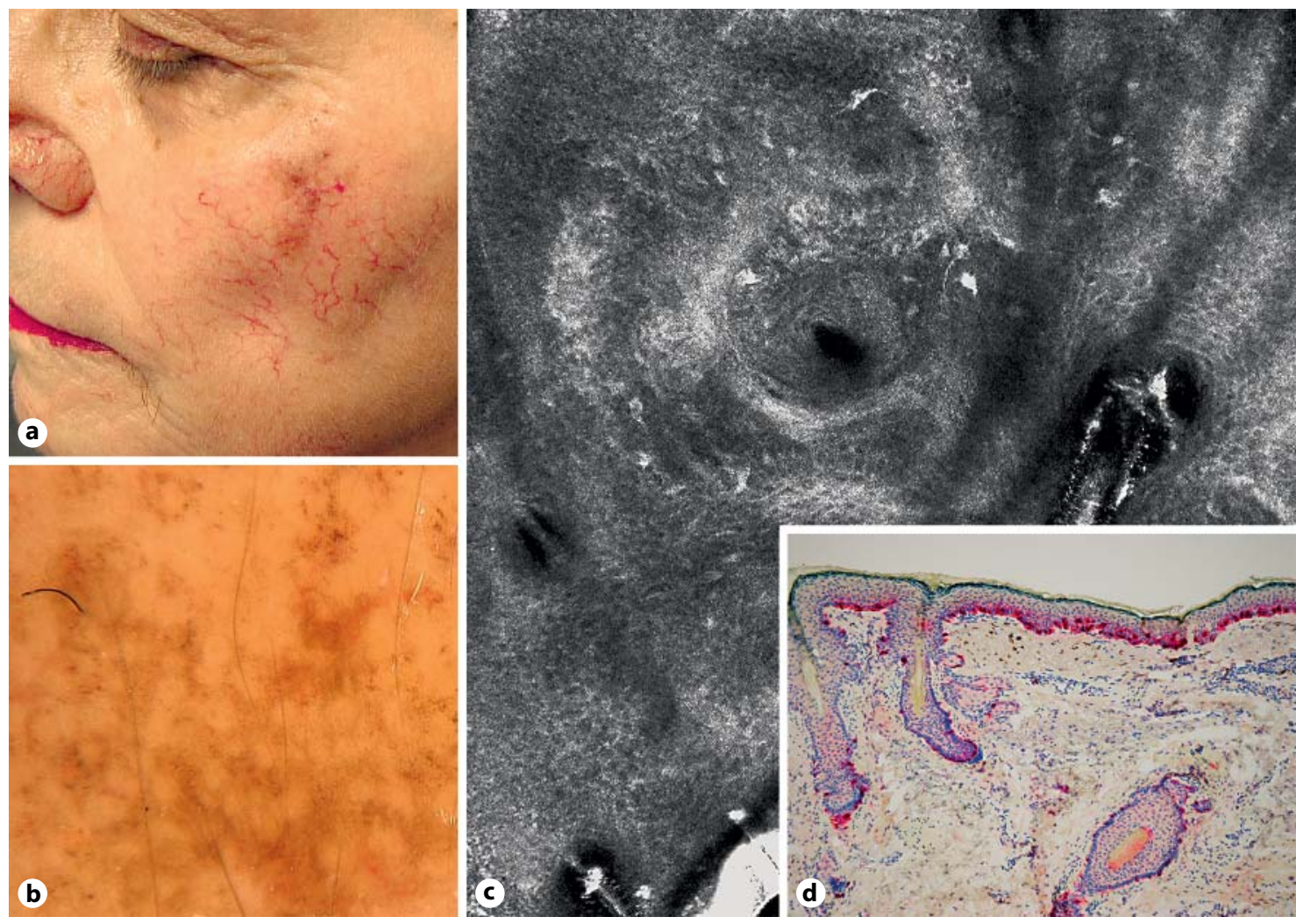

Fig. 4. Clinical (a), dermoscopic (b), confocal (c) and histological (d) picture of a recurrent LM at 12 weeks after the treatment with ingenol mebutate.

and Europa as a local treatment for actinic keratosis [710]. In addition to its approved use, ingenol mebutate has emerged in the last years as an efficient topical agent for the treatment of Bowen's disease [11], superficial basal cell carcinoma [12] and molluscum contagiosum [13].

To date, there is only one report on successful treatment of recurrent melanoma in situ with ingenol mebutate $(0.015 \%$ for 3 days) at 6 months of follow-up [5].

Ingenol mebutate has been demonstrated to induce both non-apoptotic and apoptotic cell death in several malignant cell lines, including melanoma. Analysis of murine melanoma cells in vivo and in vitro with an electron microscopy confirmed a relatively rapid necrotic cell death after disintegration of the plasma membrane and disruption of cytoplasmic organelles with a loss of mitochondrial potential, following an exposure to topical ingenol mebutate [14]. The same study demonstrated a necrosis of other tumor cell lines (including human prostate carcinoma, breast adenocarcinoma and acute leukemia) confirming cytotoxic cell death and consequently low specificity of the drug at the concentrations used for different tumor cell types. Development of a rapid, strong, cytotoxic reaction as described above was also observed in our case.

Apart from its cytotoxic properties, ingenol mebutate is a protein kinase $\mathrm{C}$ activator [15] and induces apoptosis in caspase-dependent way [16]. In an in vitro study on different melanoma cell lines, ingenol mebutate induced cell death in all of the cultured melanoma cell lines. However, only in $20 \%$ of human melanoma cell lines was cell death a result of apoptosis, the rest resulting from necrosis. The exact mechanism of melanoma cell lines sensitivity to apoptosis after treatment with ingenol mebutate has not been completely elucidated.

Cozzi et al. [17] observed that treatment with ingenol mebutate caused a selective and irreversible induction of cell senescence in only certain sensitive melanoma cell lines. BRAF genotypes of the melanoma cell lines used in the study showed no correlation with the treatment outcome, with all sensitive cell lines mutated at either NRAS or $B R A F$ loci. The authors hypothesize that the induction of senescence in some of the melanoma cell lines might have been achieved by activation of MAPK pathway. Moreover, the tumor suppressor gene HRASL3/ 
HREV107 was higher expressed in melanoma cell lines resistant to ingenol mebutate treatment. Hence, they speculate that certain criteria must be present to render melanoma cells susceptible to senescence, namely, the presence of an activating NRAS or BRAF mutation and low transcriptional levels of the MAPK inhibitor HREV107.

In our patient, treatment of LM with ingenol mebutate led to a transient clearance of melanoma cells, confirmed by RCM examination, but did not result in remission of the lesion.

The described therapeutic effect of ingenol mebutate is superficial and is therefore expected to act mainly in superficial tumors. In case of a LM, proliferating melanocytes may penetrate deep into the skin, along the adnexal structures. Hence, the reduced absorption/penetration of the drug might explain the therapeutic failure. $\mathrm{RCM}$ is a non-invasive imaging technique that enables in vivo visualization of the epidermis down to the papillary dermis in real time. Resolution is almost comparable to conventional histology. Therefore, incompletely eliminated melanoma cells from the lower levels of the hair follicle's isthmus might have been undetectable on examination. Rapid recurrence of the lesion suggests the persistence of melanoma cells. Moreover, based on the above-mentioned in vitro studies, we can hypothesize that the therapeutic failure might have been caused also by a genetically resistant type of melanoma cells or by insufficient dose of the drug needed for a complete clearance. Furthermore, the metastasizing hepatocellular carcinoma may also have hampered the immune reaction against the melanoma cells. Further studies, especially in vivo and on larger series of subjects are needed to better evaluate the efficacy of the treatment with ingenol mebutate in melanocytic tumors.

\section{Statement of Ethics}

Informed consent for image acquisition, biopsy specimen sampling and treatment (including evidence-based and off-label use) was obtained from the patient.

\section{Disclosure Statement}

The authors declare no conflict of interest.

\section{References}

1 Ciocan D, Barbe C, Aubin F, Granel-Brocard F, Lipsker D, Velten M, Dalac S, Truchetet F, Michel C, Mitschler A, Arnoult G, Buemi A, Dalle S, Bernard P, Woronoff AS, Grange F: Distinctive features of melanoma and its management in elderly patients: a population-based study in France. JAMA Dermatol 2013;149:1150-1157.

2 Tannous ZS, Lerner LH, Duncan LM, Mihm MC Jr, Flotte TJ: Progression to invasive melanoma from malignant melanoma in situ, lentigo maligna type. Hum Pathol 2000;31:705-708.

3 Erickson C, Miller SJ: Treatment options in melanoma in situ: topical and radiation therapy, excision and Mohs surgery. Int J Dermatol 2010;49:482-491.

4 Higgins HW 2nd, Lee KC, Galan A, Leffell DJ: Melanoma in situ: part II. Histopathology, treatment, and clinical management. J Am Acad Dermatol 2015;73:193-203; quiz 203204.

5 Mansuy M, Nikkels-Tassoudji N, Arrese JE, Rorive A, Nikkels AF: Recurrent in situ melanoma successfully treated with ingenol mebutate. Dermatol Ther (Heidelb) 2014;4:131135.

6 Ramsay JR, Suhrbier A, Aylward JH, Ogbourne S, Cozzi SJ, Poulsen MG, Baumann KC, Welburn P, Redlich GL, Parsons PG: The sap from Euphorbia peplus is effective against human nonmelanoma skin cancers. Br J Dermatol 2011;164:633-636

7 Lebwohl M, Shumack S, Stein Gold L, Melgaard A, Larsson T, Tyring SK: Long-term follow-up study of ingenol mebutate gel for the treatment of actinic keratoses. JAMA Dermatol 2013;149:666-670.

8 Keating GM: Ingenol mebutate gel $0.015 \%$ and $0.05 \%$ : in actinic keratosis. Drugs 2012; 72:2397-2405.

9 Ottawa (ON): Canadian Agency for Drugs and Technologies in Health: Ingenol Mebutate (Picato): Topical Treatment of Non-Hyperkeratotic, Non-Hypertrophic Actinic Keratosis in Adults. CADTH Common Drug Reviews, 2014

10 Anderson L, Schmieder GJ, Werschler WP, Tschen EH, Ling MR, Stough DB, Katsamas J: Randomized, double-blind, double-dummy, vehicle-controlled study of ingenol mebutate gel $0.025 \%$ and $0.05 \%$ for actinic keratosis. J Am Acad Dermatol 2009;60:934-943.

11 Braun SA, Homey B, Gerber PA: [Successful treatment of Bowen disease with ingenol mebutate]. Hautarzt 2014;65:848-850.

12 Cantisani C, Paolino G, Cantoresi F, Faina V, Richetta AG, Calvieri S: Superficial basal cell carcinoma successfully treated with ingenol mebutate gel 0.05\%. Dermatol Ther 2014;27: 352-354.
13 Javed S, Tyring SK: Treatment of molluscum contagiosum with ingenol mebutate. J Am Acad Dermatol 2014;70:e105.

14 Ogbourne SM, Suhrbier A, Jones B, Cozzi SJ, Boyle GM, Morris M, McAlpine D, Johns J, Scott TM, Sutherland KP, Gardner JM, Le TT, Lenarczyk A, Aylward JH, Parsons PG: Antitumor activity of 3 -ingenyl angelate: plasma membrane and mitochondrial disruption and necrotic cell death. Cancer Res 2004;64:28332839.

15 Ersvaer E, Kittang AO, Hampson P, Sand K, Gjertsen BT, Lord JM, Bruserud O: The protein kinase $\mathrm{C}$ agonist PEP005 (ingenol 3-angelate) in the treatment of human cancer: a balance between efficacy and toxicity. Toxins (Basel) 2010;2:174-194.

16 Gillespie SK, Zhang XD, Hersey P: Ingenol 3 -angelate induces dual modes of cell death and differentially regulates tumor necrosis factor-related apoptosis-inducing ligand-induced apoptosis in melanoma cells. Mol Cancer Ther 2004;3:1651-1658.

17 Cozzi SJ, Parsons PG, Ogbourne SM, Pedley J, Boyle GM: Induction of senescence in diterpene ester-treated melanoma cells via protein kinase $\mathrm{C}$-dependent hyperactivation of the mitogen-activated protein kinase pathway. Cancer Res 2006;66:1008310091. 